The Egyptian Journal of Hospital Medicine (July 2019) Vol. 76 (3), Page 3641-3646

\title{
Factors Predicting Male Satisfaction after Penile Prosthesis Implantation
}

Alsaeed Abd Elbadea Alsayed*, Magdy Mohamed Sabrh, Yaser Ali Badran

Department of Urology, Faculty of Medicine, Al-Azhar University

*Corresponding author: Alsaeed Abd Elbadea Alsayed, Mobile: +201019965424, Email: saeedaldmoky@ gmail.com

\begin{abstract}
Background: penile prosthetic surgery is associated with satisfaction rates $>90 \%$ for the general implant population. However, it is suggested that satisfaction rates may be lower in certain populations.

Objective: to analyze the factors affecting male satisfactionrates after penile prosthesis implantation (PPI).

Patients and Methods: this observational retrospective and prospective study included all patients who underwent PPI surgery at Al-Azhar University Hospitals [Al-Hussein and Sayed Galal]; Cairo; Egypt during the period from January 2015 to May 2019. One hundred and three men were eligible for the study. The age of patients, body mass index (BMI), associated medical co-morbidities, etiology of erectile dysfunction (ED), duration of ED before PPI, date of the surgery, and intra- and post-operative complications were evaluated. Men`s satisfaction with PPI was evaluated at a time point at least 6 months postoperatively by using the validated Quality of Life and Sexuality with Penile Prosthesis (QoLSPP) questionnaire. Results: seventy-six (73.8\%) subjects were highly satisfied while 27 (26.2\%) were less satisfied. The BMI of highly satisfied subjects was significantly lower than those less satisfied $\left(21.3 \pm 2.2 \mathrm{~kg} / \mathrm{m}^{2} \mathrm{vs} .27 .5 \pm 1.4 \mathrm{~kg} / \mathrm{m}^{2} ; \mathrm{p}<0.001\right)$ and a significant positive relationship was found between BMI and less satisfaction.

Conclusion: the increase in is male's BMI has a negative impact on his satisfaction levels post PPI; with every unit increase in male's BMI $>24.5 \mathrm{~kg} / \mathrm{m}^{2}$, there is increase in the risk of less satisfaction by 11.1 times.

Keywords: Penile prosthesis implantation (PPI), Satisfaction, Erectile dysfunction (ED), Quality of Life and Sexuality with Penile Prosthesis (QoLSPP) questionnaire.
\end{abstract}

\section{INTRODUCTION}

PPI is a valuable surgical treatment for erectile dysfunction and is currently proposed as a third-line treatment for patients who do not respond or reject other erectile dysfunction treatments ${ }^{(\mathbf{1})}$.

The satisfaction of the patient and the partner is the most important end point of $\mathrm{PPI}^{(2)}$. Men's satisfaction with PPI revealed (1) psychological factors include positive emotions, self-esteem, confidence, the promotion of male identity, direct living change, selfimage;(2) improve the sexual function that indicates vaginal penetration, increase sexual desire, sexual satisfaction, penis size, and improve erectile function; (3) relationship factors that indicate improved relationship and partner satisfaction ${ }^{(3,4)}$.

Advances in penile prosthetic device design and refined surgical technique have resulted in improved postoperative outcomes with fewer problems such as mechanical failure or infection ${ }^{(5)}$. Thus, patients report levels of general satisfaction as high as $90 \%{ }^{(6,7)}$. However, it is suggested that satisfaction rates may be lower in certain populations ${ }^{(\mathbf{8})}$.

Although there are several studies examining the outcomes and satisfaction rates post PPI, as far as we know the factors affecting the satisfaction levels post PPI have not been well studied.

\section{AIM OF THE WORK}

It is to analyze the factors affecting male satisfactionrates after PPI in Al-Azhar University Hospitals (Al-Hussein and Sayed Galal), Cairo, Egypt.

\section{PATIENTS AND METHODS}

This observational retrospective and prospective study included all patients who underwent PPI surgery at Al-Azhar University Hospitals (Al-Hussein and Sayed Galal), Cairo, Egypt, during the period from January 2015 to May 2019.

The Research Ethics Committee of our institution approved the study protocol and all participants provided an informed written consent before inclusion.

Patients with unstable sexual relationship, genital anomalies and gonadal hormones disturbance were excluded. One hundred and three men were eligible for inclusion.The age of patients, body mass index (BMI), associated medical co-morbidities, etiology of erectile dysfunction (ED), duration of ED before PPI, date of the surgery, and intra- and post-operative complications were evaluated. Men's satisfaction with PPI was evaluated at a time point at least 6 months postoperatively by using the Quality of Life and Sexuality with Penile Prosthesis (QoLSPP) questionnaire, which was developed and validated in a cohort of patients treated with PPI for $\mathrm{ED}^{(9)}$.

\section{Statistical Analysis}

The collected data were organized, tabulated andstatistically analyzed using statistical package forsocial science (SPSS) version 25 software.

Data were explored for normality using Kolmogrov-Smirnov test and Shapiro-Wilk test. 
Numerical data were summarized using means and standard deviations or medians and ranges. Categorical data were summarized as (numbers) percentages.

Comparisons between the 2 groups with respect to normally distributed numeric variables were done using the independent t-test. None normally distributed numeric variables were compared by Mann-Whitney test. For categorical variables, differences were analyzed with $\chi 2$ (chi square) test or Fisher's exact test when appropriate. Differences have been considered significant when probability $(p)$ value $<0.05$.

\section{RESULTS}

Out of 116 patients who underwent primary semi-rigid PPI surgery for ED, at the targeted hospitals, 103 were eligible for study. Four (3.4\%) patients refused to participate in the study (response rate: 96.6\%), 5 $(4.3 \%)$ patients lost follow up, $2(1.7 \%)$ had unstable sexual relationship and $2(1.7 \%)$ died.

The mean age of the 103 study subjects was $52.2 \pm 9.9$ years, the mean BMI was $22.9 \pm 3.4$, and the mean duration of ED was $24.2 \pm 11.1$ months.

Sixty-three $(61.2 \%)$ subjects had diabetes mellitus (DM), 26 (25.2\%) with hypertension (HTN), 24 $(23.3 \%)$ with ischemic heart disease (IHD), 1 (0.97\%) with epilepsy, $1(0.97 \%)$ with hemiplegia.

Of the 103 subjects with severe ED, 90 (87.4\%) subjects had venous leakage, $17(16.5 \%)$ had arterial insufficiency, and 2 (1.9\%) had fracture penis.

All the study subjects underwent semi-rigid PPI during the period from 2015 to 2019,18 (17.5\%) subjects at $2015,23(22.3 \%)$ at $2016,19(18.4 \%)$ at 2017,21 (20.4\%) at 2018, and $22(21.4 \%)$ at 2019.

Six (5.8\%) subjects had corporal crossover which was corrected intraoperatively and PPI was completed, and 2 (1.9\%) had urethral catheter fixation to the corpus cavernosum during closure of corporotomy. Urethral catheter fixation discovered early postoperatively. The catheter was left and slipped after one month as the vicryl sutures were absorbed.

Postoperative complications were minor complications including superficial wound infection in 8 (7.8\%) subjects, and penoscrotal hematoma in $3(2.9 \%)$ subjects. All these complications resolved with conservative treatment.

As regard functional, relational, social and personal domains of the QOLSPP questionnaire, 76 (73.8\%) subjects were highly satisfied while 27 (26.2\%) were less satisfied.
The age of highly satisfied subjects was significantly lower than those less satisfied $(50.1 \pm 10.0$ years vs. 58.0 \pm 7.0 years; $\mathrm{p}<0.001$ ). The BMI of highly satisfied subjects was significantly lower than those less satisfied $(21.3 \pm 2.2 \mathrm{~kg} / \mathrm{m} 2$ vs. $27.5 \pm 1.4 \mathrm{~kg} / \mathrm{m} 2 ; \mathrm{p}<0.001)$ (Table 1).

BMI and age were entered in logistic regression model, only BMI was statically significant i.e. BMI independently affect satisfaction. There is a positive relationship between BMI and less satisfaction, with every unit increase in BMI; there is increase in the risk of less satisfaction by 11.1 times (Table 2).

Receiver operating characteristics (ROC) analysis was done for BMI, the best cut off point was 24.5 $\mathrm{kg} / \mathrm{m} 2$ with 1.00 sensitivity and 0.87 specificity. The area under the curve was $0.99, \mathrm{p}$ value $=0.000$ and $95 \%$ Confidence Interval (CI) was 0.97 and 1.00 for lower and upper boundaries respectively (Figure 1).

Table (1): Analysis of age and BMI in relation to functional, relational, social and personal satisfaction

\begin{tabular}{|c|c|c|c|c|c|}
\hline & Satisfaction & Count & Mean & SD & value \\
\hline \multirow[t]{3}{*}{ Age } & Highly & 76 & 50.1 & 10.0 & \multirow{3}{*}{$<0.001$} \\
\hline & Satisfied & & & & \\
\hline & $\begin{array}{r}\text { Less } \\
\text { Satisfied }\end{array}$ & 27 & 58.0 & 7.0 & \\
\hline \multirow[t]{3}{*}{ BMI } & Highly & 76 & 21.3 & 2.2 & \multirow{3}{*}{$<0.001$} \\
\hline & Satisfied & & & & \\
\hline & $\begin{array}{r}\text { Less } \\
\text { Satisfied }\end{array}$ & 27 & 27.5 & 1.4 & \\
\hline
\end{tabular}

BMI: body mass index, SD: standard deviation, $\mathrm{p} \leq 0.05$

is considered statistically significant

Table (2): Logistic regression analysis of BMI of study subjects in relation to functional, relational, social and personal satisfaction

\begin{tabular}{|l|c|c|c|c|c|}
\hline & \multirow{2}{*}{ S.E. } & P value & \multirow{2}{*}{ OR } & \multicolumn{2}{|c|}{ 95\% CI for OR } \\
\cline { 5 - 6 } & & & & Lower & Upper \\
\hline BMI & 0.80 & 0.003 & 11.1 & 2.3 & 53.6 \\
\hline Constant & 20.5 & 0.003 & .000 & & \\
\hline
\end{tabular}

SE: standard error, $\mathrm{p} \leq 0.05$ is considered statistically

significant, OR: odds ratio, CI: confidence interval

No significant difference was found between highly satisfied and less satisfied subjects regarding the duration of ED before PPI $(23.6 \pm 11.9$ months vs. $25.9 \pm 8.6$ months $)(p=0.353)$.

No significant difference was found between highly satisfied and less satisfied subjects regarding the frequency of DM, HTN and IHD (Table 3). 


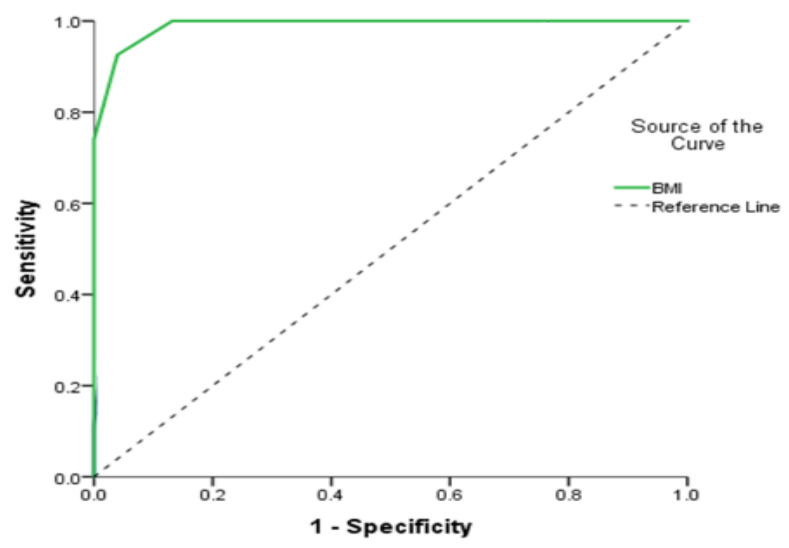

Figure (1): ROC curve of BMI of study subject

Table (3): The frequency of associated medical co-morbidities in highly satisfied subjects and those less satisfied in relation to functional, relational, social and personal satisfaction

\begin{tabular}{|c|c|c|c|c|c|c|}
\hline & \multicolumn{4}{|c|}{$\begin{array}{l}\text { Satisfaction } \\
\end{array}$} & \multirow[b]{3}{*}{ p value } \\
\hline & & \multicolumn{2}{|c|}{ Highly Satisfied } & \multicolumn{2}{|c|}{ Less Satisfied } & \\
\hline & & Count & $\%$ & Count & $\%$ & \\
\hline \multirow{2}{*}{ DM } & No & 33 & 43.4 & 7 & 25.9 & \multirow{2}{*}{0.109} \\
\hline & Yes & 43 & 56.6 & 20 & 74.1 & \\
\hline \multirow{2}{*}{ HTN } & No & 55 & 72.4 & 22 & 81.5 & \multirow{2}{*}{0.345} \\
\hline & Yes & 21 & 27.6 & 5 & 18.5 & \\
\hline \multirow{2}{*}{ IHD } & No & 58 & 76.3 & 21 & 77.8 & \multirow{2}{*}{0.877} \\
\hline & Yes & 18 & 23.7 & 6 & 22.2 & \\
\hline
\end{tabular}

DM: diabetes mellitus, HTN: hypertension, IHD: ischemic heart disease, $p \leq 0.05$ is considered statistically significant

Table (4): The main etiologies of ED in highly satisfied subjects and those less satisfied in relation to functional, relational, social and personal satisfaction

\begin{tabular}{|c|c|c|c|c|c|c|}
\hline \multirow{2}{*}{} & \multicolumn{5}{|c|}{ Satisfaction } \\
\cline { 2 - 7 } & & Highly Satisfied & \multicolumn{2}{c|}{ Less Satisfied } & \\
\cline { 2 - 7 } Venous leakage & Count & \% & Count & \% & p value \\
\hline \multirow{2}{*}{$\begin{array}{c}\text { Arterial } \\
\text { Insufficiency }\end{array}$} & Yes & 65 & 85.5 & 25 & 92.6 & 0.342 \\
\cline { 2 - 7 } & No & 65 & 85.5 & 21 & 77.8 & \multirow{2}{*}{0.352} \\
\hline \multirow{2}{*}{ Fracture Penis } & No & 11 & 14.5 & 6 & 22.2 & \\
& Yes & 2 & 97.4 & 27 & 100.0 & \multirow{2}{*}{1.000} \\
\hline
\end{tabular}

$\mathrm{p} \leq 0.05$ is considered statistically significant. No significant difference was found between highly satisfied and less satisfied subjects regarding the frequency of venous leakage, arterial insufficiency and fracture penis (Table 4).

Table (5): Analysis of the intraoperative and postoperative complications in highly satisfied subjects and those less satisfied in relation to functional, relational, social and personal satisfaction

\begin{tabular}{|c|c|c|c|c|c|c|}
\hline & & \multicolumn{4}{|c|}{ Satisfaction } & \multirow[b]{3}{*}{ p value } \\
\hline & & \multicolumn{2}{|c|}{ Highly Satisfied } & \multicolumn{2}{|c|}{ Less Satisfied } & \\
\hline & & Count & $\%$ & Count & $\%$ & \\
\hline \multirow{2}{*}{$\begin{array}{l}\text { Intraoperative } \\
\text { complications }\end{array}$} & No & 71 & 93.4 & 24 & 88.9 & \multirow{2}{*}{0.450} \\
\hline & Yes & 5 & 6.6 & 3 & 11.1 & \\
\hline \multirow{2}{*}{$\begin{array}{l}\text { Postoperative } \\
\text { complications }\end{array}$} & No & 69 & 90.8 & 23 & 85.2 & \multirow{2}{*}{0.418} \\
\hline & Yes & 7 & 9.2 & 4 & 14.8 & \\
\hline
\end{tabular}

$\mathrm{p} \leq 0.05$ is considered statistically significant. No significant difference was found between highly satisfied and less satisfied subjects regarding the frequency of intraoperative complications and postoperative complications (Table 5).

No significant difference was found between highly satisfied and less satisfied subjects regarding the duration post PPI ( $2.1 \pm 1.3$ years vs. $1.8 \pm 1.2$ years $)(\mathrm{p}=0.200)$. 


\section{DISCUSSION}

Previous studies assessing outcomes after PPI used non-validated tools to assess sexual satisfaction and patients' QoL ${ }^{(2,10)}$.

In other surveys, validated measures, such as either the International Index of Erectile Function (IIEF) or the Erectile Dysfunction Inventory of Treatment Satisfaction (EDITS), have been applied for a more accurate evaluation of postoperative outcomes ${ }^{(7,11,12)}$, however, those tools were designed and validated to assess patients treated with oral therapy, intracavernous injections or vacuum erection devices ${ }^{(\mathbf{1 3 , 1 4})}$ as such, they may be unable to assess accurately functional outcomes and patient satisfaction after PPI ${ }^{(2)}$.

The use of either a non-validated questionnaire or a tool developed in a non-PPI population could lead to an improper estimation of patient satisfaction. Indeed, with both strategies, we could miss the evaluation of some relevant aspects dealing with QoL, such as the relationship with the partner, as well as functional aspects, such as device operability and simplicity of use, which are all relevant to penile prosthesis surgery ${ }^{(2,3)}$.

To provide a reliable tool able to simultaneously evaluate perceived penile prosthesis function and postoperative QoL, Caraceni and Utizi ${ }^{(\mathbf{9})}$ designed the Quality of Life and Sexuality with Penile Prosthesis (QoLSPP) questionnaire, a validated questionnaire that specifically examined patient's quality of life after PPI and the extent to which a PP affects the patient's sexual quality of life (SQoL).

The main outcome measure of the QoLSPP is quality of life as biological and psychosocial-relational well-being after penile prosthesis placement. It has 16 questions encompassing 4 domains investigating: prosthesis function (functional); relationship with partner (relational); relation to the outside world (social); and self-image (personal) ${ }^{(\boldsymbol{9})}$.

In our study, we applied QoLSPP questionnaire for providing more reliable data in terms of patient satisfaction after PPI.

In our study the etiology of ED has no effect on male satisfaction rates post PPI, thus confirming recent studies that have reported that they did not observe an association between ED etiology and patient satisfaction scores $^{(4,15)}$.

In our study, we found that the age of the patient has no effect on his satisfaction rates post PPI, thus confirming studies that have reported that they did not observe an association between age and patient satisfaction, even after using a questionnaire specifically investigating the simplicity of use of the implanted device
(4). Akin-Olugbadeet al. ${ }^{(8)}$ have reported that a body mass index $>30 \mathrm{~kg} / \mathrm{m}^{2}$ has been associated with dissatisfaction after penile prosthesis surgery. This also has been shown through lower EDITS scores in this group compared with the general population. In our study, there is a positive relationship between BMI and less satisfaction. With every unit increase in BMI > 24.5 $\mathrm{kg} / \mathrm{m}^{2}$, there is increase in the risk of less satisfaction by 11.1 times.

Some data indicate that obese patients have a higher risk for ED than those with a normal body mass index $(\leq 25 \mathrm{~kg} / \mathrm{m} 2)$ because of abnormal endothelial function and psychological factors ${ }^{(16,17)}$.

Such factors could contribute to impairments in sexual $\mathrm{QoL}^{(\mathbf{1 8})}$. Thus, obese patients might harbor lower satisfaction at baseline before penile implantation that could explain lower postoperative satisfaction.

In our study, we did not observe an association between the duration of ED before PPI and the male satisfaction rates post PPI, thus confirming recent studies that have reported that the duration of ED preoperatively, had no significant impact on patient satisfaction following penile prosthesis surgery ${ }^{(8)}$.

In our study, we did not observe an impact of postoperative complications on male satisfaction rates post PPI. These results are in agreement with the results of Capogrosso et al. ${ }^{(4)}$.

Some long-term studies (mean follow-up range $=$ 59-105 months) reported consistently high levels of satisfaction with a mean EDITS score of $73.11^{(\mathbf{1 0}, \mathbf{1 9}, \mathbf{2 0})}$.

In their study, Akakpo et al. ${ }^{(2)}$ found that patient satisfaction tends to increase in the first year after surgery, and after which it reaches a plateau. In our study, we did not observe an association between the duration after PPI and the male satisfaction rates post PPI.

\section{STUDY LIMITATIONS}

No one of our study subjects underwent inflatable PPI due to high cost of that device. The PPI surgeries were done by different surgeons with different levels of experience that could not be measured. However, we did not observe an impact of intraoperative and postoperative complications on male satisfaction rates post PPI.

\section{CONCLUSION}

The increase in is male's BMI has a negative impact on his satisfaction levels post PPI; with every unit increase in male's BMI $>24.5 \mathrm{~kg} / \mathrm{m}^{2}$, there is increase in the risk of less satisfaction by 11.1 times.Despite some limitations, the observed information can be found reliable for generalization. Physicians and other health 
professionals should pay attention to the psychological status of those patients and provide them with proper preoperative counselling to achieve the maximum benefits of this surgery.

\section{REFERENCES}

1. Levine LA, Becher E, Bella A et al. (2016): Penile prosthesis surgery: current Recommendations from the international consultation on sexual medicine. J Sex Med., 13: 489-518.

2. Akakpo W, Pineda MA, and Burnett AL (2017): Critical Analysis of Satisfaction Assessment After Penile Prosthesis Surgery. Sex Med Rev., 5: 244-251.

3. Carvalheira A, Santana R, and Pereira NM (2015): Why are men satisfied or dissatisfied with penile implants? A mixed method study on satisfaction with penile prosthesis implantation. J Sex Med., 12: 2474-2480.

4. Capogrosso P, Pescatori E, Caraceni E et al. (2019): Satisfaction rate at 1-year follow-up in patients treated with penile implants: data from the multicentre prospective registry INSIST-ED. BJU Int., 123(2): 360-366.

5. Le B, and Burnett AL (2015): Evolution of penile prosthetic devices. Korean J Urol., 56:179-186.

6. Pryor MB, Carrion R, Wang $R$ et al. (2016): Patient satisfaction and penile morphology changes with postoperative penile rehabilitation 2 years after Coloplast Titan prosthesis. Asian J Androl., 18:754-758.

7. Pillay B, Moon D, Love C et al. (2017): Quality of life, psychological functioning, and treatment satisfaction of men who have undergone penile prosthesis surgery following robot-assisted radical prostatectomy. J Sex Med., 14:1612-1620.

8. Akin- Olugbade O, Parker M, Guhring P et al. (2006): Determinants of patient satisfaction following penile prosthesis surgery. The Journal of Sexual Medicine, 3(4): 743-748.

9. Caraceni E and Utizi L (2014): A questionnaire for the evaluation of quality of life after penile prosthesis implant: quality of life and sexuality with penile prosthesis (QoLSPP): to what extent does the implant affect the patient's life? J Sex Med., 11:1005-1012.

10. Montorsi F, Rigatti P, Carmignani G et al. (2000): Ams three- piece inflatable implants for erectile dysfunction: A long- term multi-institutional study in 200 consecutive patients. European Urology, 37(1): 50-55.

11. Natali A, Olianas $R$, and Fisch $M$ (2008): Penile implantation in Europe: successes and complications with 253 implants in Italy and Germany. J Sex Med., 5:15031512.

12. Chung E, Solomon M, DeYoung L et al. (2014): Clinical outcomes and patient satisfaction rates among elderly male aged $\geq 75$ years with inflatable penile prosthesis implant for medically refractory erectile dysfunction. World J Urol., 32:173-177.

13. Rosen RC, Riley A, Wagner G et al. (1997): The international index of erectile function (IIEF): a multidimensional scale for assessment of erectile dysfunction. Urology, 49: 822-830.

14. Althof SE, Corty EW, Levine SB et al. (1999): EDITS: development of questionnaires for evaluating satisfaction with treatments for erectile dysfunction. Urology, 53: 793799.

15. Vakalopoulos I, Kampantais S, Ioannidis S et al. (2013): High patient satisfaction after inflatable penile prostheses implantation correlates with female partner satisfaction. J Sex Med., 10:2774-2781.

16. Bacon CG, Mittleman MA, Kawachi I et al. (2003): Sexual function in men older than 50 years of age: results from the health professionals' follow-up study. Annals of Internernal Medicine, 139:161-168.

17. Esposito K, Giugliano F, Di Palo C et al. (2004): Effect of lifestyle changes on erectile dysfunction in obese men: a randomized controlled trial. Journal of American Medical Association, 291:2978-2984.

18. Kolotkin RL, Binks M, Crosby RD et al. (2006): Obesity and sexual quality of life. Obesity (Silver Spring), 14:472479.

19. Vitarelli A, Divenuto L, Fortunato F et al. (2013): Long term patient satisfaction and quality of life with AMS700CX inflatable penile prosthesis. Arch Ital Urol Androl., 85:133137.

20.Ji YS, Ko YH, Song PH et al. (2015): Long-term survival and patient satisfaction with inflatable penile prosthesis for the treatment of erectile dysfunction. Korean J Urol., 56:461-465. 